\title{
HUBUNGAN ANTARA BELAJAR BERDASAR REGULASI DIRI DENGAN SIKAP TERHADAP EKSTRAKURIKULER PADA SISWA KELAS XI SMA MARDISISWA SEMARANG
}

\author{
Randwitya Ayu Ganis Hemasti \\ Email: randwitya.ganis@ubpkarawang.ac.id
}

Fakultas Psikologi Universitas Buana Perjuangan Karawang

\begin{abstract}
This study aimed to determine the relationship between learning based on selfregulation with attitudes toward extracurricular activities, and to determine the effective contribution of learning based on self-regulation. The population in accordance with the characteristics in this study amounted to 113 students in Mardisiswa Semarang High School. Data collection uses a scale of learning based on self-regulation consisting of 31 items $(\alpha=$ 0.939), and a scale of attitude towards extracurricular consisting of 30 items $(\alpha=0.970)$. The results of hypothesis testing show that learning based on self-regulation is positively related to attitudes towards extracurricular activities indicated by rxy $=0.529$ with a significance level of correlation of $0,000(\mathrm{p}<0.05)$. The test results obtained coefficient of determination of 0,280 . It means that learning based on student self-regulation gives an effect of $28 \%$ on attitudes toward extracurricular. While $72 \%$ of attitudes towards extracurricular are influenced by other factors outside the variables of this study. These factors include personal experience, the influence of others who are considered important, the influence of culture, mass media, religious institutions, and the influence of emotional factors.
\end{abstract}

Keywords: self-regulation, Extracurricular.

Abstrak. Penelitian ini ditujukan untuk mengetahui hubungan antara belajar berdasar regulasi diri dengan sikap terhadap ekstrakurikuler, dan untuk mengetahui sumbangan efektif belajar berdasar regulasi diri. Populasi yang sesuai dengan karakteristik dalam penelitian ini berjumlah 113 siswa di SMA Mardisiswa Semarang. Pengumpulan data menggunakan skala belajar berdasar regulasi diri yang terdiri dari 31 item $(\alpha=0,939)$, dan skala sikap terhadap ekstrakurikuler yang terdiri dari 30 item $(\alpha=0,970)$.Hasil pengujian hipotesis menunjukkan bahwa belajar berdasar regulasi diri berhubungan secara positif dengan sikap terhadap ekstrakurikuler yang ditunjukkan dengan $r_{x y}=0,529$ dengan tingkat signifikansi korelasi sebesar $0,000(\mathrm{p}<0,05)$. Hasil pengujian diperoleh nilai koefisiensi determinasi sebesar 0,280 . Artinya adalah belajar berdasar regulasi diri siswa memberikan pengaruh sebesar 28\% terhadap sikap terhadap ekstrakurikuler. Sedangkan $72 \%$ sikap terhadap ekstrakurikuler dipengaruhi oleh faktor-faktor lain di luar variabel penelitian ini. Faktor- faktor tersebut antara lain adalah pengalaman pribadi, pengaruh orang lain yang dianggap penting, pengaruh kebudayaan, media massa, lembaga agama, dan pengaruh faktor emosional

31 | Psychophedia Jurnal Psikologi Universitas Buana Perjuangan Karawang 


\section{Pengantar}

Di dalam dunia pendidikan sekarang, perlu adanya pendidikan karakter untuk siswa. Pendidikan karakter tidak hanya cukup diajarkan melalui mata pelajaran di dalam kelas saja. Sebab, sekolah dapat menerapkannya melalui kegiatan-kegiatan pembiasaan untuk membentuk karakter siswa. Kegiatan-kegiatan itu dapat dilaksanakan secara intrakurikuler dan ekstrakurikuler.

Kegiatan intrakurikuler dilaksanakan terintegrasi ke dalam mata pelajaran yang relevan, dan kegiatan ekstrakurikuler dilaksanakan di luar mata pelajaran. Kegiatan pembiasaan melalui ekstrakurikuler dapat dilakukan di luar jam pelajaran, selama kurang lebih empat jam setiap minggu (Saktia, 2010). Hal ini dilakukan untuk memfasilitasi pengembangan potensi siswa dan pendidikan karakter siswa. Di sekolah, siswa mengikuti jam pelajaran hanya sekitar delapan jam dan setelah itu ada kegiatan tambahan berupa ekstrakurikuler (Riana, 2012). Dalam hal ini, seharusnya siswa mempunyai kegiatan positif di luar jam sekolah yaitu dengan mengikuti kegiatan ekstrakurikuler. Ekstrakurikuler sudah menjadi bagian dari siswa, karena selain sebagai wadah untuk berorganisasi juga sebagai ajang eksistensi diri (Ekskul Asik yang Patut Kamu Ikuti, 2011). Gilman, Meyers, dan Peres (2004: 31) menyatakan bahwa aktivitas terstruktur terhadap ekstrakurikuler (structured extracurricular activities) merupakan suatu strategi yang potensial untuk membentuk resiliensi para remaja yang dapat mendukung perilaku pro sosial keterikatan di sekolah dan aktivitas yang sesuai, membentuk performa akademis dan tumbuh dengan subjective well-being. Hal tersebut juga didukung pernyataan dari Ryan (Gilman, Meyers, dan Peres, 2004: 31) yaitu keterikatan terhadap aktivitas di sekolah dapat mengembangkan rasa memiliki serta memiliki motivasi akademis. Menurut Suryosubroto (2009, h. 288) ruang lingkup ekstrakurikuler adalah berupa kegiatan-kegiatan yang dapat menunjang dan dapat mendukung program intrakurikuler yaitu mengembangkan pengetahuan dan kemampuan penalaran siswa, ketrampilan melalui hobi dan minat serta pengembangan sikap yang ada pada program intrakurikuler dan program ekstrakurikuler.

Menurut Ormrod (2008: 29) siswa juga harus mampu menguasai pengetahuan dan keterampilan yang membuat prestasi mereka tinggi, di kelas. Beberapa pengetahuan dan keterampilan itu bersifat spesifik untuk topik-topik dan mata pelajaran tertentu, tetapi keterampilan dalam pengaturan diri (self-regulation skill) dapat memiliki pengaruh bagi prestasi siswa di mana pun. Pengaturan diri menjadi semakin 
penting saat usia remaja dan dewasa, ketika banyak aktivitas belajar seperti membaca, mengerjakan pekerjaan rumah (PR), surfing internet. Aktivitas tersebut terjadi tanpa kehadiran dan keterlibatan orang lain dan karena itu mensyaratkan pengarahan diri (self-direction) (Ormrod, 2008: 41). Berdasarkan pernyataan tersebut, peneliti menyimpulkan pengaturan diri itu menunjang prestasi akademis.

\section{Landasan Teori}

\section{Regulasi Diri}

Menurut Slavin (2011: 10) belajar berdasar regulasi diri adalah kemampuan siswa yang mempunyai pengetahuan dalam menggunakan strategi pembelajaran yang efektif dalam menggunakannya. Misalnya, mereka dapat mengurai soal yang sulit menjadi lebih mudah dalam mengerjakannya dan mampu memahami solusi alternatif dalam menggunakannya agar lebih mudah dalam menulis dan menginformasikannya. Menurut Zimmerman (dalam Slavin, 2011: 108) siswa yang sangat termotivasi mempelajari sesuatu daripada siswa lain lebih cenderung dengan sadar merencanakan pembelajaran, melaksanakan rencana pembelajaran, dan mengingat informasi yang mereka peroleh. Ekstrakurikuler perlu disiasati oleh sekolah, supaya siswa mampu mengelola dan merencanakan agenda keseharian sehingga antara akademis dan kegiatan non akademis tidak berbenturan.

Kemampuan untuk mengelola aktivitas-aktivitas yang ada dalam kegiatan siswa dikenal sebagai belajar berdasar regulasi diri. Eagle dan Chaiken (dalam
Myers, 2012: 63) menjelaskan komponen sikap sebagai ABC (affect, behavior, cognition) sikap yaitu perasaan, tendensi perilaku, dan kognisi (pikiran) terhadap ekstrakurikuler.(1) Perasaan yaitu menyangkut masalah emosional subjektif seseorang terhadap suatu objek sikap terhadap ekstrakurikuler. Secara umum, komponen ini disamakan dengan perasaan yang dimiliki terhadap ekstrakurikuler. Namun, pengertian perasaan pribadi seringkali sangat berbeda perwujudannya bila dikaitkan dengan sikap terhadap ekstrakurikuler. (2) Kognisi (pikiran) yaitu berisi kepercayaan seseorang mengenai apa yang berlaku atau apa yang benar bagi objek sikap terhadap ekstrakurikuler. (3) Tendensi perilaku yaitu struktur sikap menunjukkan bagaimana perilaku atau kecenderungan berperilaku yang ada dalam diri seseorang berkaitan dengan objek sikap yang dihadapinya. Kaitan ini didasari oleh asumsi bahwa kepercayaan dan perasaan banyak mempengaruhi perilaku.

Menurut Ormrod (2008: 38) aspek belajar berdasar regulasi diri adalah prosesproses yang pada dasarnya bersifat metakognitif: (1). Penetapan tujuan (goal setting) yaitu pembelajar yang mengatur diri tahu apa yang ingin mereka capai ketika membaca atau belajar, mempelajari faktafakta yang spesifik, mendapatkan pemahaman konseptual yang luas tentang suatu topik (2). Perencanaan (planning) yaitu pembelajar yang mengatur diri sendiri sebelumnya sudah menentukan bagaimana baiknya menggunakan waktu dan sumber 
daya yang tersedia untuk tugas-tugas belajar. (3). Motivasi diri (self-motivation) yaitu pembelajar yang mengatur diri biasanya memiliki self-efficacy yang tinggi akan kemampuan mereka menyelesaikan suatu tugas belajar dengan sukses. (4) Kontrol atensi (attention control) yaitu pembelajar yang mengatur diri berusaha memfokuskan perhatian mereka pada pelajaran yang sedang berlangsung dan menghilangkan dari pikiran mereka hal-hal lain yang mengganggu. (5) Penggunaan strategi belajar yang fleksibel (flexible use of learning strategies) yaitu pembelajar yang mengatur diri memiliki strategi belajar yang berbeda tergantung tujuan-tujuan spesifik yang ingin mereka capai. (6) Monitor diri (self-monitoring) yaitu pembelajar yang mengatur diri terus memonitori kemajuan mereka dalam kerangka tujuan yang telah diterapkan, dan mereka mengubah strategi belajar atau memodifikasi tujuan bila dibutuhkan. (7) Mencari bantuan yang tepat (appropriate help seeking) yaitu pembelajar yang benar-benar mengatur diri tidak selalu harus berusaha sendiri. Sebaliknya, mereka menyadari bahwa mereka membutuhkan bantuan orang lain dan mencari bantuan semacam itu. (8) Evaluasi diri (selfevaluation) yaitu pembelajar yang (mampu) mengatur diri menentukan apakah yang mereka pelajari itu telah memenuhi tujuan awal mereka.

\section{Metode Penelitian}

Metode analisis statistik yang dipergunakan dalam penelitian ini adalah analisis regresi sederhana. Analisis regresi sederhana digunakan untuk mengadakan peramalan atau prediksi besarnya variasi yang terjadi pada variabel kriterium berdasarkan variabel prediktor, menentukan bentuk hubungan antara variabel prediktor dengan variabel kriterium, serta menentukan arah dan besarnya koefisien korelasi antara variabel prediktor dengan variabel kriterium (Winarsunu, 2004: 177).

Populasi pada penelitian ini adalah 113 siswa di SMA Mardisiswa, Semarang. Skala yang digunakan dalam penelitian ini adalah dua skala yaitu skala sikap terhadap ekstrakurikuler dan skala belajar berdasar regulasi diri. Kedua skala ini menggunakan skala model Likert dengan empat pilihan respon, yaitu Sangat Setuju (SS), Setuju (S), Tidak Setuju (TS), dan (STS) Sangat Tidak Setuju dan terdiri dari pernyataan favourable (mendukung) dan unfavourable (tidak mendukung). Pemberian skor pada aitem favourable adalah $\mathrm{SS}=4, \mathrm{~S}=3, \mathrm{TS}=2$, STS $=1$ sedangkan penilaian terhadap aitem unfavourable $\mathrm{SS}=1, \mathrm{~S}=2, \mathrm{TS}=3, \mathrm{STS}=$ 4.

Perhitungan untuk mencari indeks daya beda aitem dengan menggunakan analisis statistik SPSS. Dalam penelitian ini, peneliti menggunakan validitas isi (content validity) untuk mengestimasi pengujian terhadap tes. Menurut Azwar (2010, h. 46) estimasi validitas ini tidak melibatkan perhitungan statistik apapun melainkan hanya analisis rasional, maka tidaklah diharapkan setiap orang akan sama sependapat mengenai sejauhmana validitas 
isi suatu tes telah tercapai. Untuk menguji reliabilitas dalam penelitian ini, yaitu dengan menggunakan teknik Alpha Cronbach. 1. Uji normalitas, digunakan untuk menguji apakah data sampel yang diambil dari populasi mengikuti suatu distribusi normal statistik (Winarsunu, 2004, h. 277). Uji normalitas dilakukan dengan menggunakan teknik statistik uji Kolmogorov-Smirnov Goodness of Fit Test.

\section{Hasil Dan Pembahasan}

$\begin{array}{ccc}\text { Hasil } & \text { pengujian } & \text { hipotesis } \\ \text { menunjukkan } & \text { bahwa belajar } & \text { berdasar }\end{array}$ regulasi diri berhubungan secara positif dengan sikap terhadap ekstrakurikuler yang ditunjukkan dengan $r_{x y}=0,529$ dengan tingkat signifikansi korelasi sebesar 0,000 $(\mathrm{p}<0,05)$. Hasil pengujian diperoleh nilai koefisiensi determinasi sebesar 0, 280. Artinya adalah belajar berdasar regulasi diri siswa memberikan pengaruh sebesar $28 \%$ terhadap sikap terhadap ekstrakurikuler. Sedangkan $72 \%$ sikap terhadap ekstrakurikuler dipengaruhi oleh faktorfaktor lain di luar variabel penelitian ini. Faktor- faktor tersebut antara lain adalah pengalaman pribadi, pengaruh orang lain yang dianggap penting, pengaruh kebudayaan, media massa, lembaga agama, dan pengaruh faktor emosional.

Berdasarkan uji normalitas terhadap belajar berdasar regulasi diri didapatkan signifikansi nilai Kolmogorov Smirnov sebesar 0,725 dengan nilai $\mathrm{p}=0,669$ ( $>0,05)$. Hasil tersebut menunjukkan bahwa sebaran data belajar berdasar regulasi diri memiliki distribusi normal.

Berdasarkan uji normalitas terhadap sikap terhadap ekstrakurikuler didapatkan signifikansi nilai Kolmogorov Smirnov sebesar 0,914 dengan nilai $\mathrm{p}=0,373$ $(\mathrm{p}>0,05)$. $\mathrm{F}$ tes dalam perhitungan ini menghasilkan $\mathrm{F}$ hitung sebesar 43,083 dengan tingkat signifikansi $\mathrm{p}=0,000$ $(\mathrm{p}<0,05)$. Maka dapat disimpulkan bahwa terdapat hubungan linier antara variabel belajar berdasar regulasi diri dengan sikap terhadap ekstrakurikuler.

Hasil yang diperoleh dari pengujian hipotesis dengan teknik analisis regresi sederhana menunjukkan bahwa terdapat hubungan yang positif antara belajar berdasar regulasi diri dengan sikap terhadap ekstrakurikuler pada siswa SMA Mardisiswa. Tanda positif pada angka koefisien korelasi menunjukkan bahwa arah hubungan kedua variabel adalah positif. Hal ini mengindikasikan bahwa semakin tinggi belajar berdasar regulasi diri, maka semakin positif sikap terhadap ekstrakurikuler pada siswa SMA Mardisiswa. Begitu juga sebaliknya, semakin rendah belajar berdasar regulasi diri, maka semakin negatif sikap terhadap ekstrakurikuler pada siswa SMA Mardisiswa.

\section{Kesimpulan}

Berdasarkan hasil penelitian yang telah diperoleh, maka dapat dibuat kesimpulan sebagai berikut:

1. Terdapat hubungan yang positif antara belajar berdasar regulasi diri 
dengan sikap terhadap ekstrakurikuler pada SMA Mardisiswa Semarang. Hal ini menunjukan bahwa semakin tinggi belajar berdasar regulasi diri, maka akan semakin positif sikap terhadap ekstrakurikuler. Begitu juga sebaliknya, semakin rendah belajar berdasar regulasi diri maka akan semakin negatif sikap terhadap ekstrakurikuler pada siswa SMA Mardisiswa. Hal tersebut dapat dilihat dari naiknya kualitas sikap terhadap ekstrakurikuler merupakan akibat dari naiknya kualitas belajar berdasar regulasi diri dari siswa.

2. Belajar berdasar regulasi diri mempunyai sumbangan efektif sebesar $28 \%$ terhadap sikap terhadap ekstrakurikuler. Hal ini menunjukan aspek belajar berdasar regulasi diri berpengaruh terhadap komponen sikap terhadap ekstrakurikuler sebesar 28\%. Sisanya $72 \%$ ditentukan oleh faktor lain yang tidak menjadi tujuan dari penelitian ini, yaitu menurut Azwar (2011: 30) pengalaman pribadi, pengaruh orang lain yang dianggap penting, pengaruh kebudayaan, media massa, lembaga agama, pengaruh faktor emosional.

\section{Kepustakaan}

Alwisol. (2009). Psikologi kepribadian. Malang: UMM Press.
Azwar, S. (2011). Sikap manusia. Yogyakarta: Pustaka Pelajar.

Azwar, S. (2010). Reliabilitas dan validitas.Yogyakarta: Pustaka Pelajar.

Azwar, S. (2012). Penyusunan skala psikologi. Yogyakarta: Pustaka Pelajar.

Azwar, S. (2012). Metode penelitian. Yogyakarta: Pustaka Pelajar.

Boekaerts, M., Pintrich, P. R., \& Zeidner, M. (2002). Handbook of selfregulation. California: Academic Press.

Duckworth, K., Akerman, R., MacGregor, A., Salter, E., \& Vorhaus, J. (2009). Self-Regulated learning: A literature review. London: Learning Institute of Education.

Feldman, P. O. (2009). Human development. Edisi 10 buku 2. Jakarta: Salemba Humanika

Gilman, R., Meyers, J., \& Peres L. (2004). Structured extracurricular activities among adolescents: Findings and implications for school psychologists, 41, 31-41. Doi:10.1002/pits.10136.

Irwanto. (2002). Psikologi umum. Jakarta: PT Prenhallindo

Myers, D. G. (2012). Psikologi sosial. Jakarta: Salemba Humanika.

Nunez, J.C., Carezo, R., Bernando, A., Rosario, P., Valle, A., Fernandez, E., $\&$ Suarez, N. (2015). Implementation of Training Program in SelfRegulated Learning Strategies in Moodle Format: Result of a Experience in Higher Education 23, 274-281. 0214-9915

Ormrod, J. E. (2008). Psikologi pendidikan. Jakarta: Erlangga.

36 | Psychophedia Jurnal Psikologi Universitas Buana Perjuangan Karawang 
Riana. (2011, Desember). Ekstrakurikuler Tak Ampuh Atasi Tawuran Pelajar. Diambil dari http://edukasi.kompas.com/read/201 1/12/03/11102034/Ekstrakurikuler.T ak.Ampuh.Atasi.Tawuran.Pelajar.

Richards, G. (2010). Psikologi. Yogyakarta: Pustaka Baca.

Rosidi. (2012, April). Mantapkan Berbahasa Inggris dengan Outbond. Diambil dari http://www.suaramerdeka.com/v1/in dex.php/read/news/2012/04/01/1141 63/Mantapkan-Berbahasa-Inggrisdengan-Outbond.

Santoso, L. H. (2010). Kamus lengkap bahasa Indonesia. Surabaya: Pustaka Agung Harapan

Santrock, J. W. (2012). Life-span development. Edisi 13 jilid 1. Jakarta: Erlangga.

Sarwono, W. (2012). Pengantar psikologi umum. Jakarta: PT RajaGrafindo.

Slavin, R. E. (2011). Psikologi pendidikan. Jakarta: PT Indeks.

Sobur, A. (2009). Psikologi итит. Bandung: CV Pustaka Setia.

Solso, R., Machlin, O.H., \& Machlin, M. K. (2008). Psikologi kognitif: Edisi Kedelapan. Jakarta: Erlangga.

Sugiono. (2008). Metode penelitian kuantitatif kualitatif dan $R \& D$. Bandung: Alfabeta.

Sukadji, S. (2000). Menyusun dan mengevaluasi laporan penelitian. Jakarta: Universitas Indonesia.

Suryosubroto, B. (2009). Proses belajar mengajar di sekolah. Jakarta: Rineka Cipta

Susanto, H. (2006). Mengembangkan kemampuan self-regulation untuk menungkatkan keberhasilan akademik siswa. Jurnal Pendidikan Penabur, 07, 64-71.

Winarsunu, T. (2004). Statistik dalam penelitian psikologi dan pendidikan. Malang: UMM Press.

Winkel, W. S. (2009). Psikologi pengajaran. Yogyakarta: Media Abadi. 